\title{
Pituitary deficiency and precocious puberty after childhood severe traumatic brain injury: a long-term follow-up prospective study
}

\author{
Yamina Dassa', Hélène Crosnier ${ }^{1}$, Mathilde Chevignard ${ }^{2}, 3$, Magali Viaud ${ }^{1}$, Claire Personnier ${ }^{4}$, Isabelle Flechtner ${ }^{1}$, \\ Philippe Meyer,5,6, Stéphanie Puget ${ }^{6,7}$, Nathalie Boddaert ${ }^{6,8}$, Sylvain Breton ${ }^{8}$ and Michel Polak ${ }^{1,6,9}$ \\ ${ }^{1}$ Paediatric Endocrinology, Gynaecology and Diabetology Unit, Assistance Publique-Hôpitaux de Paris, Necker Enfants-Malades \\ University Hospital, Paris, France, ${ }^{2}$ Rehabilitation Department for Children and Adolescents with Acquired \\ Neurological Injury, Saint-Maurice Hospitals, Saint-Maurice, France, ${ }^{3}$ Laboratoire d'Imagerie Biomédicale and GRC \\ HanCRe, Sorbonne University, Paris, France, ${ }^{4} \mathrm{CHI}$ Poissy-St Germain, Poissy, France, ${ }^{5}$ Paediatric Anaesthesiology \\ Unit, Assistance Publique-Hôpitaux de Paris, Necker Enfants-Malades University Hospital, Paris, France, ${ }^{6}$ Paris \\ Descartes University, Paris, France, ${ }^{7}$ Paediatric Neurosurgery Unit, ${ }^{8}$ Radiology Unit, Assistance Publique-Hôpitaux de \\ Paris, Necker Enfants-Malades University Hospital, Paris, France, and ${ }^{9}$ MAGINE Institute Affiliate, Paris, France \\ Correspondence \\ should be addressed \\ to $\mathrm{H}$ Crosnier \\ Email \\ h.savajol-crosnier@orange.fr
}

\begin{abstract}
Objectives: Childhood traumatic brain injury (TBI) is a public health issue. Our objectives were to determine the prevalence of permanent pituitary hormone deficiency and to detect the emergence of other pituitary dysfunctions or central precocious puberty several years after severe TBI.

Design: Follow-up at least 5 years post severe TBI of a prospective longitudinal study.

Patients: Overall, 66/87 children, who had endocrine evaluation 1 year post severe TBI, were included (24 with pituitary dysfunction 1 year post TBI).

Main outcome measures: In all children, the pituitary hormones basal levels were assessed at least 5 years post TBI. Growth hormone (GH) stimulation tests were performed 3-4 years post TBI in children with GH deficiency (GHD) 1 year post TBI and in all children with low height velocity ( $<-1$ DS) or low IGF-1 ( $<-2$ DS). Central precocious puberty (CPP) was confirmed by GnRH stimulation test.

Results: Overall, 61/66 children were followed up 7 (5-10) years post TBI (median; (range)); 17/61 children had GHD 1 year post TBI, and GHD was confirmed in 5/17 patients. For one boy, with normal pituitary function 1 year post TBI, GHD was diagnosed 6.5 years post TBI. 4/61 patients developed CPP, 5.7 (2.4-6.1) years post-TBI. Having a pituitary dysfunction 1 year post TBI was significantly associated with pituitary dysfunction or CPP more than 5 years post TBI. Conclusion: Severe TBI in childhood can lead to permanent pituitary dysfunction; GHD and CPP may appear after many years. We recommend systematic hormonal assessment in children 1 year after severe TBI and a prolonged monitoring of growth and pubertal maturation. Recommendations should be elaborated for the families and treating physicians.
\end{abstract}

\section{Introduction}

Traumatic brain injury (TBI) in children and adolescents is a major public health issue worldwide and approximately $3-6 \%$ of TBI is severe $(1,2,3,4,5)$. Severe TBI, defined according to the Glasgow Coma Scale (GCS $\leq 8)(6)$, is a frequent cause of childhood mortality and permanent physical and psychological disability. Twenty to fifty percent of children suffer disabilities and cognitive deficits, while behavioural and/or psychiatric disorders are reported in $10-50 \%(7,8,9,10)$. Retrospective and prospective paediatric studies reported variable rates

Published by Bioscientifica Ltd. 
of hypopituitarism after TBI, mainly growth hormone deficiency (GHD) $(11,12,13,14,15,16)$. The variations in the reported frequency of GHD reflect patient selection, timing of testing and methodological heterogeneity in the evaluation of GH secretion. In children, little is known of the natural history over a long-term period of post-TBI pituitary function. Prospective studies are mostly performed over short periods of time, during the first 12 months post TBI $(17,18,19,20,21)$, and some authors challenge the reality of permanent endocrine deficiency $(22,23,24)$. The modalities of pituitary function monitoring following childhood TBI remain under discussion $(25,26)$, and there are no consensus guidelines, whereas they have been established for adults (27). Even if post-TBI GHD may be transient, as has been reported in adults $(28,29)$, we cannot exclude the development of permanent pituitary deficiency or central precocious puberty (CPP) several years post injury, which may contribute significantly to overall morbidity. Finally the duration of transient GHD is not known in children and its deleterious impact on the child's growth, body composition, recovery and quality of life cannot be excluded $(30,31)$.

Previously, in a prospective study including 87 children with severe TBI (32), we reported a rate of $33 \%$ pituitary dysfunction, mainly affecting GH secretion (31\%), 1 year post injury, without being able to identify predictive factors. In this study, we report the prolonged follow-up of this cohort. Our study has focused on children affected by severe TBI, which represent a small proportion of all children with TBI. This selected population benefit of guidelines (33) for their acute medical management.

The primary aim of this study was to determine the prevalence of permanent pituitary deficiency and to detect the development of other pituitary dysfunction and pubertal abnormalities. The secondary purpose was to identify any characteristics that were predictive of permanent endocrine dysfunction.

\section{Subjects and methods}

A prolonged clinical and endocrine follow-up on the initial cohort (32) was conducted at least 5 years post TBI, between January 2008 and April 2017. In brief the initial study's inclusion criteria were (32) chronological age (CA) less than 15 years at injury; severe TBI, defined as initial GCS score $\leq 8$ for accidental TBI (ATBI), and defined as the presence of an acute subdural hematoma requiring neurosurgical intensive care management for inflicted TBI
(ITBI) compatible with shaken baby syndrome (SBS) and supported by social investigation; parents' consent for participation. French Research Ethics Committee (CPP) approved the prolonged follow-up and written informed consent was obtained from parents of all participants.

Children with normal pituitary function 1 year post TBI (32) were contacted for the hormonal evaluation 5 years post TBI; children with pituitary deficiency 1 year post TBI benefitted from subsequent regular clinical assessment at the Department of Paediatric Endocrinology of the Necker-Enfants Malades Hospital. During the follow-up, a full clinical examination was performed at each appointment. Height (HT), weight (WT), height velocity (HV) and BMI were standardised for French reference $(34,35)$ and pubertal staging was assessed according to the method of Tanner (36). Precocious puberty (PP) was defined as Tanner stage 2 breast development before the age of 8 years in girls, and as testicular length of $25 \mathrm{~mm}$ or more before the age of 9 years in boys. Delayed puberty was defined as Tanner stage 1-breast development after 13 years of age in girls and as testicular length of $25 \mathrm{~mm}$ after 14 years of age in boys. Mid parental height (MPH) SDS was calculated according to the equation (HT (SDS) father + HT (SDS) mother)/2) (37). Near adult height (NAH) was defined as the height measured at a $\mathrm{CA} \geq 17$ years in boys and $\geq 15$ years in girls with a $\mathrm{HV}<2 \mathrm{~cm} /$ year.

Basal $(8: 00 \mathrm{~h})$ cortisol, ACTH, insulin-like growth factor 1 (IGF-1), free T4 (fT4), free T3 (fT3), thyroidstimulating hormone (TSH) and prolactin were measured. Plasma/serum concentrations of luteinizing hormone (LH), follicle-stimulating hormone (FSH) and testosterone (male) or oestradiol (female) were assessed in girls over 10 years, boys over 11 years and in children showing clinical evidence of PP. Baseline hormone values were measured by immunoassays and compared with normal ranges provided by laboratory; IGF-1 values were compared with normal reference ranges according to age, sex and pubertal stage.

Dynamic tests (arginine-insulin test, glucagonpropranolol test) were systematically performed between 3 and 4 years after TBI in children with GHD (two stimulated GH peak $<7 \mu \mathrm{g} / \mathrm{L} 1$ year post TBI) (32), independently of auxologic criteria. In addition, dynamic tests (arginine-insulin test, glucagon-propranolol test, insulin tolerance test) and test of nocturnal GH secretion were performed in all children with HV $<-1$ DS observed during the follow-up and low $(<-2$ DS) to low-normal $(<-1$ DS) IGF-1 levels. We did not use any sex hormone priming in prepubertal subjects prior to GH stimulation test. GH (SI 98/574, $1 \mu \mathrm{g} / \mathrm{L}=3 \mu \mathrm{IU} / \mathrm{mL}$ ) was measured by 
immunoassay. GHD was defined as stimulated GH peak $<7 \mu \mathrm{g} / \mathrm{L}$ at two different provocative tests; low nocturnal $\mathrm{GH}$ secretion was defined as highest GH concentration $<7 \mu \mathrm{g} / \mathrm{L}$ and mean $\mathrm{GH}<2 \mu \mathrm{g} / \mathrm{L}$. Low to low-normal IGF-1 levels supported the diagnosis of GHD (38). A gonadotropin stimulation test ( $\mathrm{GnRH}, 100 \mu \mathrm{g} / \mathrm{m}^{2}$ i.v.) was performed in patients showing clinical evidence of PP. CPP was confirmed by stimulated LH peak $>4 \mathrm{mUI} / \mathrm{L}$. Patients with low basal cortisol level underwent a Synacthen test (0.25 $\mathrm{mg}$ as an i.v. push). ACTH deficiency was confirmed in case of stimulated cortisol peak $<550 \mathrm{nmol} / \mathrm{L}$.

All the included patients had cranial computed tomography (CT) at the acute phase, immediately post TBI. In addition, initial and post-operative head and intracranial injuries, documented by CT and (or) magnetic resonance imaging (MRI), were retrospectively analysed by the same two experienced neuroradiologists (32). Fractures of the basal skull, sella, cranial vault and facial bones, pituitary and pituitary stalk lesions, cerebral oedema, sub/epidural and traumatic subarachnoid haemorrhage, intra-cerebral parenchymal hematoma and intra-cerebral (supra or infra-tentorial) petechial haemorrhages were recorded.

Patients data were expressed as mean \pm S.D. if there was a Gaussian distribution or median (ranges) if there was a non-Gaussian distribution. Differences in patientsreported data were tested with Fisher's exact test or Wilcoxon-Mann-Whitney test; correlations were tested with Pearson test. A $P$ value $<0.05$ was considered to be significant.

\section{Results}

Among the 87 eligible children enrolled in the first study (32), 66 were included of which five decided to interrupt the follow-up 3.5 years (median; range (3.5-4.8 years)) post TBI (Fig. 1). The remaining 61 children were followed up beyond 5 years post TBI (median; (range), 7 (5-10) years). The characteristics of included patients are summarised in Table 1.

\section{Endocrine evaluation}

\section{GH secretion and auxological evaluation}

Among the 61 patients with long follow-up, 17 patients had GHD 1 year post TBI; 12/17 patients had normalised their GH secretion 3.5-4.5 years post injury. All these patients had normal HV since the first assessment at 1 year post TBI. Among the five patients who left the

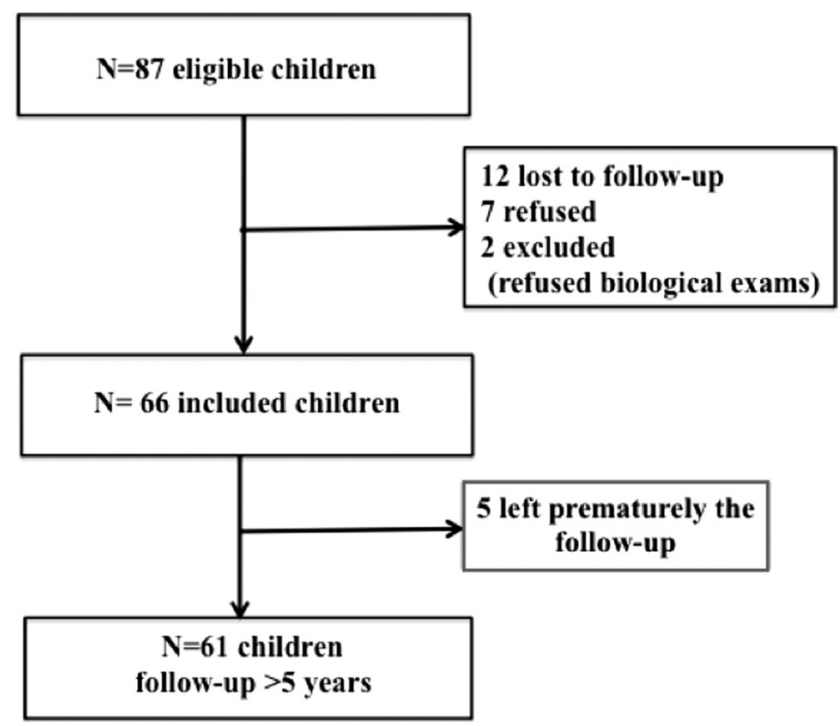

Figure 1

Patients flow chart.

study prematurely, three had normalised GH secretion $4.2,4.7$ and 4.8 years respectively post TBI. The other two patients, tested 3.5 and 3.8 years post TBI had a low GH response under stimulation (GH peak $5.5 \mu \mathrm{g} / \mathrm{L}$ and $3 \mu \mathrm{g} / \mathrm{L}$ respectively) but were overweight (SDS BMI 2.4 and 4.2 respectively) and had normal IGF-1, a normal HV with normal HT (HT SDS 1.2 and 3 respectively) (Fig. 2).

Persistent GHD was confirmed in six patients (Tables 2 and 3) and five of them required GH treatment initiated 1.2-6.7 years after injury because of a low HV. No new dynamic GH test was performed on the patient $n^{\circ} 96$ who was overweight, but pubertal (Tanner stage 3) with low HV ( -3.7 SDS) and low IGF-1 ( -2 SDS). For one boy $\left(n^{\circ} 9\right)$, with normal pituitary function 1 year post TBI, GHD was diagnosed 6.6 years post TBI and required GH treatment. Patient $n^{\circ} 42$ had TSHD associated with GHD and received L-thyroxin treatment; his HV remained within normal ranges ( -1 SDS). None of the patients with GHD received other medication.

At their last assessment, 6.8 years post TBI (median; range (5.4-10 years)) 19/61 patients (14 males, 19 ATBI) had completed their puberty and reached AH or NAH. Among these 19 patients, the patient $\mathrm{n}^{\circ} 1$ treated with GH 1.3 years after TBI had normal AH close to MPH (0.63 vs $0.33 \mathrm{SDS}$ ). For the other 18 patients, $\mathrm{AH}$ and $\mathrm{NAH}$ were significantly correlated with $\mathrm{MPH}(-0.07 \pm 0.9$ vs $-0.18 \pm 0.58$ SDS; $P=0.005$ ).

At their last assessment mean SDS BMI of young adults patients and growing patients were not significantly different $(0.6 \pm 2$ vs $0.8 \pm 1.7 ; P=0.8)$. Among the 42 
Table 1 Characteristics of included patients.

\begin{tabular}{|c|c|c|c|c|c|}
\hline Cause of injury $(n)$ & Gender & $\begin{array}{c}\text { CA1 (years), median } \\
\text { (range) }\end{array}$ & $\begin{array}{c}\text { TS 1-year post } \\
\text { TBI }(n)\end{array}$ & $\begin{array}{c}\text { Pituitary function } \\
\text { 1-year post TBI }\end{array}$ & $\begin{array}{c}\text { CA2 (years), median } \\
\text { (range) }\end{array}$ \\
\hline \multicolumn{6}{|c|}{ (A) $n=61$ children followed beyond five years } \\
\hline ITBI (9) & $1 \mathrm{~F} / 8 \mathrm{M}$ & $0.5(0.2-1.2)$ & $\begin{array}{l}\text { S1 (8) } \\
\text { G1 (1) }\end{array}$ & $\begin{array}{c}6 \text { normal } \\
3 \text { GHD }\end{array}$ & $8.9(7.4-10)$ \\
\hline ATBI (52) & $15 \mathrm{~F} / 37 \mathrm{M}$ & $7.8(2.5-14.4)$ & S1 (11) & 35 normal & $14.9(7.5-21.8)$ \\
\hline Fall (15) & & & $\mathrm{S} 2-3 \mathrm{RO}(2)$ & 14 GHD & \\
\hline RA (35) & & & S4R1 (2) & $1 \mathrm{GHD}+\mathrm{TSHD}$ & \\
\hline Pedestrian (22) & & & G1 (24) & 1 TSHD & \\
\hline Cyclists (7) & & & G2-3 (6) & 1 ACTHD & \\
\hline MVA (6) & & & G4-5 (7) & 1 low GH peak & \\
\hline \multicolumn{6}{|l|}{ Others (2) } \\
\hline \multicolumn{6}{|c|}{ (B) $n=5$ children followed $<5$ years } \\
\hline ATBI (5) & $1 \mathrm{~F} / 4 \mathrm{M}$ & $4.5(0.7-7.1)$ & S1 (1) & $5 \mathrm{GHD}$ & $8.1(4.2-12.3)$ \\
\hline Fall (1) & & & G1 (4) & & \\
\hline \multicolumn{6}{|l|}{ RA (4) } \\
\hline \multicolumn{6}{|l|}{ Pedestrian (3) } \\
\hline MVA (1) & & & & & \\
\hline
\end{tabular}

ACTHD, ACTH deficiency; ATBI, accidental TBI; CA1, chronological age at injury; CA2, chronological age at last hormonal assessment; F, female; GHD, GH deficiency (two stimulated GH peak <7 $\mu \mathrm{g} / \mathrm{L}$ ); ITBI, inflicted TBI; M, male; MVA, motor vehicle accident; $n$, number of children; RA, road accident; TDHS, TSH deficiency; TS, Tanner stage.

growing children, mean SDS BMI of children without GHD and children who developed GHD at least 1 year post TBI did not differ significantly $(0.96 \pm 1.39$ vs $0.73 \pm 1.26$; $P>0.99$ ).

\section{Puberty}

Excluding patients with short follow-up, 4/61 patients experienced CPP, 5.7 years (median; range (2.4-6.1)) post injury (Table 4) and required GnRH analogue treatment. There was no family history for CPP (maternal first menstruation at $13.7 \pm 0.6$ years). Two of these patients (study number 14 and 65) with GHD 1 year post TBI assessment had recovered normal GH secretion 3 and 3.5 years post TBI.

The 19/61 young adults or adolescents who had reached $\mathrm{AH}$ had not experienced delayed or arrested puberty after TBI. All 14 pubertal males had testosterone levels within their age-appropriate reference range and secondary amenorrhea or dysmenorrhoea were not observed in the five young women.

In the $38 / 61$ younger patients, 18 were in puberty at their last assessment, without delay.

\section{TSH axis}

One girl and one boy with TSH deficiency 1 year post TBI required L-thyroxin treatment during the whole follow-up. FT4 remained low in the girl until the end of paediatric follow-up at 19.5 years, 6.4 years post TBI; in the boy, fT4 remained low or normal-low with mild elevated TSH (6.86-9.05 mIU/L; normal range $0.6-4.45 \mathrm{mIU} / \mathrm{L})$ associated with GHD, 8 years post TBI.

\section{ACTH axis}

One boy was treated by hydrocortisone since 1 year post TBI. The basal cortisol and cortisol responses after

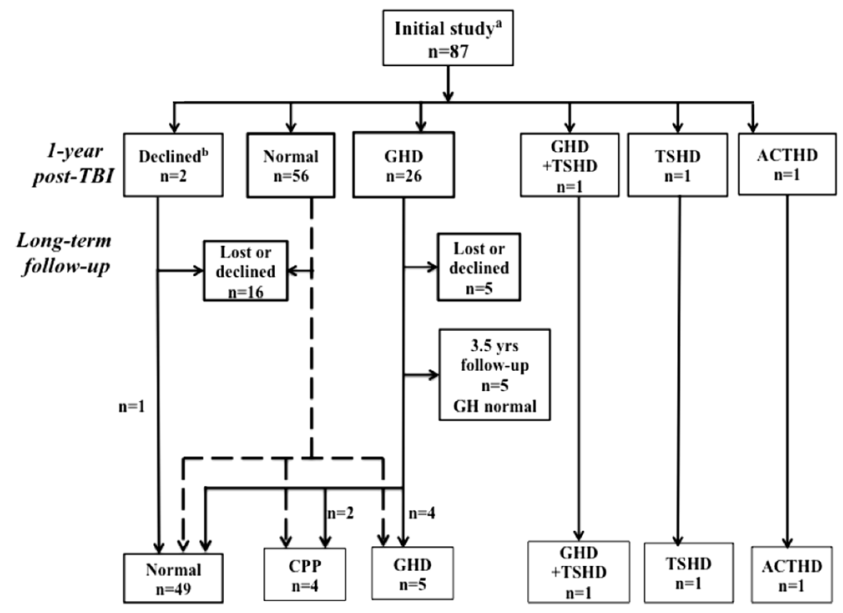

\section{Figure 2}

Results of endocrine evaluation 1 year post TBI and at the last follow-up (a), referenced to (32); (b), one patient who had interrupted the assessment prematurely 1 year post TBI accepted the long follow-up study; ACTHD, ACTH deficiency; CPP, central precocious puberty; GHD, GH deficiency; normal, normal pituitary function; TSHD, TSH deficiency. 
Table 2 Patients with GHD.

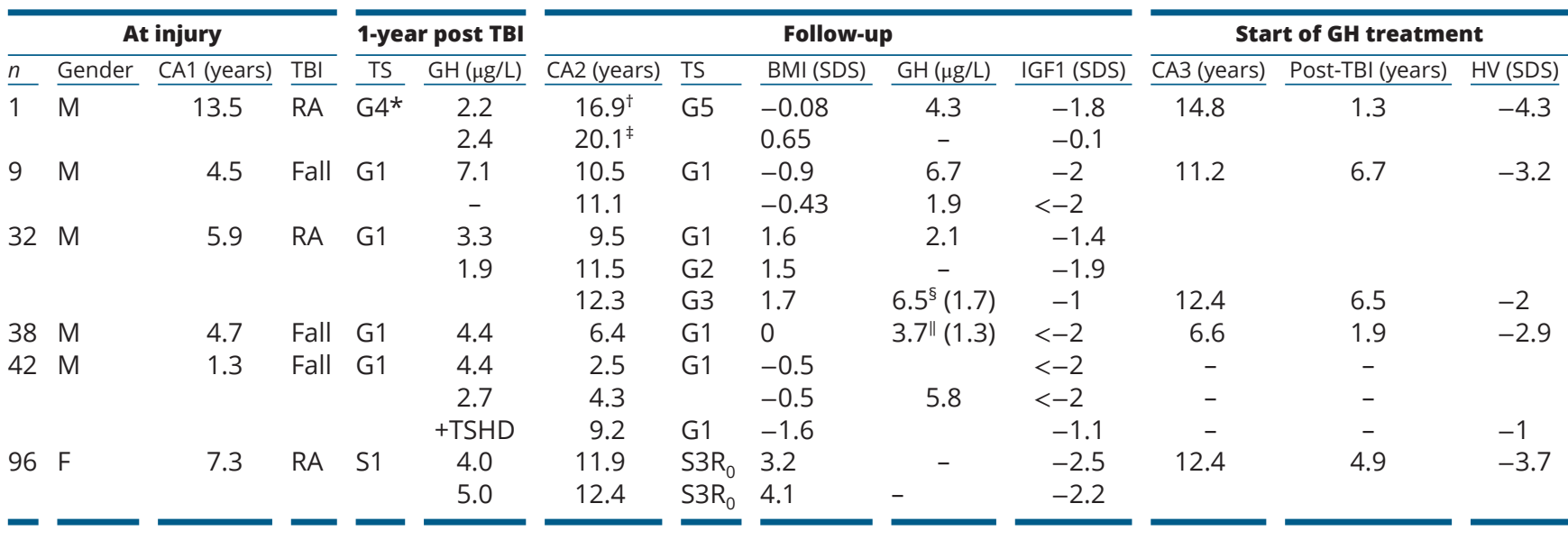

Results at 1 year post TBI are referenced from (32).

*Testosterone level: 3.4 and $4.6 \mathrm{ng} / \mathrm{mL}^{*}{ }^{\dagger}$ three months after the end of GH treatment; ${ }^{*}$ testosterone level: $8.2 \mathrm{ng} / \mathrm{mL} ;{ }^{5, \| n o c t u r n a l ~ G H}$ peak (mean GH secretion).

BMI, body mass index; CA1, chronological age at injury; CA2, chronological age during follow-up; CA3, chronological age at start of GH treatment; $F$, female; GH, stimulated GH peak; HV, height velocity; M, male; $n$, study number; RA, road accident, pedestrian; TBI, nature of injury; TS, Tanner stage; + TSHD, TSH dysfunction associated.

stimulation by Synacthen remained low until the CA of 17.3 years. At this time, 5.7 years post TBI, adrenal function has normalised and the treatment was stopped.

\section{Other endocrine functions}

Prolactin levels were normal in all the patients. No patient exhibited sign of posterior pituitary dysfunction during the follow-up.

\section{Predictive factors}

A pituitary dysfunction 1 year post TBI was significantly associated with pituitary dysfunction $(\mathrm{GH}, \mathrm{ACTH}, \mathrm{TSH}$ function) or CPP, more than 5 years after severe TBI $(P=0.006)$. No patient or TBI severity characteristics (gender, age and TS at injury, nature of TBI, hemodynamic instability, length of intubation, polytraumatism or neurologic disabilities) were significantly associated with the presence or absence of pituitary dysfunction or CPP at the time of last follow-up.

All the 61 patients had cranial CT during the acute phase, immediately post TBI. For 59 of them CT and MRI were reported by a neuroradiologist (56 of initial CT and three MRI performed in early post-operative period). No radiological parameter, type of lesion or location of lesion was significantly associated with the development of pituitary deficiency or CPP.

\section{Discussion}

We report the natural history of pituitary function in $61 / 87$ (67\%) of patients of our original cohort (32) from 1 year to a median of 7 years after severe TBI. During this follow-up, we observed that 8/61 (13\%) patients had

Table 3 Patients with GHD.

\begin{tabular}{|c|c|c|c|c|c|c|}
\hline$n$ & 1 year before TBI & 1-2 years post-TBI & 2-4 years post-TBI & 4-6 years post-TBI & 6-8 years post-TBI & $8-10$ years post-TBI \\
\hline 1 & 0 & $-4.3(a)$ & 3.2 & 2.0 & 1.2 & $\mathrm{AH}$ \\
\hline 9 & -0.3 & 0.2 & 0.03 & -1.67 & $-3.2(a)$ & 2.75 \\
\hline 34 & 0.9 & -0.2 & 1.35 & $-2(a)$ & $\begin{array}{c}2.9 \\
5.67\end{array}$ & $\mathrm{NAH}$ \\
\hline 38 & 0.9 & $\begin{array}{c}1.2 \\
-2.9(a)\end{array}$ & 2.7 & 4.3 & 1.5 & -2 \\
\hline 42 & 1 & -1.2 & -0.18 & -2.15 & -1.02 & - \\
\hline 96 & -0.9 & -1.3 & 0.03 & $-3.7(a)$ & 5.45 & - \\
\hline
\end{tabular}

Data on height velocity (expressed in SDS for chronological age) during the follow-up.

(a), start of $\mathrm{GH}$ treatment; $\mathrm{AH}$, adult height; $n$, study number; $\mathrm{NAH}$, near adult height. 
Table 4 Characteristics of patients with central precocious puberty (CPP).

\begin{tabular}{|c|c|c|c|}
\hline \multicolumn{4}{|c|}{ At injury } \\
\hline$n$ & Gender & CA1 (years) & Nature of injury \\
\hline 14 & $\mathrm{~F}$ & 5.1 & RA, cyclist \\
\hline 24 & $F$ & 1.5 & Fall \\
\hline 65 & M & 3.1 & RA, MVA \\
\hline 94 & $F$ & 1.2 & Fall \\
\hline
\end{tabular}

\begin{tabular}{|c|c|c|c|}
\hline \multicolumn{4}{|c|}{ At start of puberty } \\
\hline CA2 (years) & BMI (SDS) & $\mathrm{HV}$ (SDS) & LH peak (mlU/L) \\
\hline 7.5 & 3.1 & 2.5 & 17.9 \\
\hline 7 & 1.7 & 2.9 & 14.3 \\
\hline 9 & 0.9 & 3.4 & 24.1 \\
\hline 7.3 & 0.4 & 3.2 & 4.1 \\
\hline
\end{tabular}

\begin{tabular}{|c|c|c|}
\hline \multicolumn{3}{|c|}{ Hormonal evaluation } \\
\hline 1-year post-TBI & At last evaluation & CA3 (years) \\
\hline GHD & Normal & 12.8 \\
\hline Normal & Normal & 14.3 \\
\hline GHD & Normal & 10.8 \\
\hline Normal & Normal & 7.7 \\
\hline
\end{tabular}

CA1, chronological age at injury; CA2, chronological age at start of puberty; CA3, chronological age at the last hormonal evaluation; F, female; GHD, GH deficiency; HV, height velocity; LH peak, under stimulation by GnRH; M, male; MVA, motor vehicle accident; $n$, number study; RA, road accident.

pituitary dysfunction (10\% GHD, 3\% TSH deficiency and $2 \%$ prolonged ACTH deficiency) and 4/61 (7\%) CPP. The rate of GHD (6/61 in our cohort) was higher than the prevalence of childhood GHD in general population (39). Our results are consistent with many previous studies conducted in adults $(29,40)$ or with cross-sectional studies in children (16).

Not surprisingly, the long-term follow-up of these children was difficult as reported by a recent study (41), which stated a $46 \%$ rate of non or partial adherence to medical follow-up in children after severe TBI. In our study, we experienced the same difficulties of non or partial adherence. Overall, the retention rate in our cohort was high for such a long-term follow-up.

As reported in adult patients $(29,40)$, early GHD observed 1 year post TBI was transient in the majority of children. However, 5/22 (23\%) of patients with GHD 1 year post TBI remained deficient, with biological and auxological criteria $(38,42,43)$. Two patients (No. 34 and No.38) had an evaluation of nocturnal GH secretion. Given the appearance of a reduced $\mathrm{HV}$, we wanted to confirm GHD. Each of them had two or three provocative tests the years(s) before with low GH responses. For psychological reasons (the two boys showed great reluctance to undergo a new provocative test), with the agreement of parents and patients, we have decided to use a nocturnal GH secretion test.

Five of these patients needed rhGH treatment because of poor growth observed over a few years post injury. Interestingly, in one other child with normal pituitary function 1 year post TBI, GHD was identified and diagnosed several years after TBI through the routine clinical follow-up of growth. In agreement with Bellone et al. (44), we believe that a systematic close monitoring of growth is needed in the long term in outpatient clinics after TBI, in order to recognise a permanent GHD. However, Moon et al. (45) reported great difficulties obtaining satisfactory height and weight documentation. It also seems necessary to determine other parameters to better identify children at risk of developing a permanent GHD.

Regardless of the HV, a controversial issue is whether patients with a transient or permanent GHD should be treated early with GH. GHD may have a role in postconcussion syndrome. It has been reported that GHD may interfere with cognitive and physical rehabilitation of children with severe brain injury (30). Several studies have demonstrated beneficial effects of GH treatment on cognitive function in patients with other aetiologies $(46,47)$. In adults with GHD after TBI, a few studies have reported an improvement of cognition and quality of life (QOL) on GH therapy $(48,49,50)$ and the same result has been reported in children (51). However, in recent large study conducted in adults, only a very limited relationship between pituitary hormone deficiencies and QOL has been demonstrated due to the dominating influence of concurrent comorbidities (52). Thus, in children with early GHD diagnosed 1 year post TBI, transient or permanent, further randomised clinical trials examining the effects of early GH treatment are needed to assess the potential impact on recovery, rehabilitation and QOL.

As we suggested in our previous study (32), four cases of CPP, three girls and one boy, were diagnosed several years post injury. However we cannot exclude that our patients are at the lower end of the current normal range for pubertal maturation. Recent data suggest that age at breast development onset is becoming earlier. However, different studies suggest that age at gonadotropin surges has not changed and the lower age at initial breast development in an increasing proportion of early pubertal girls does not seem to be caused by GnRH activation (53). In our study, the three girls had a rapid breast development observed at 7-7.5 years, with precocious increased HV. In addition their mothers had menarche at a normal age and no case of CPP was reported in their family. These clinical observations associated with the results of GnRH tests were strong arguments in favour of a diagnosis of CPP. A testicular enlargement was observed 
by paediatric endocrinologist in the boy $n^{\circ} 65$ at the age of 9 that had probably begun some months before the clinical assessment. Moreover, the HV had increased from the mean to +3.4 SDS the year before. For these reasons, we have postulated that central activation of puberty began before 9 years, and consequently, we made the diagnosis of CPP. In our study the observed incidence was higher than the national incidence of CPP in France (54). In most of the studies, the reported incidence of PP after TBI is low $(16,55)$. They have not been compared to the national incidence except in one study (24) in which the incidence of CPP did not differ from the incidence in general population, but all children had not reached the normal age of pubertal onset. The majority of previous prospective studies have been conducted over a too short period to observe any possible CPP and only one prospective study (19) described three cases of CPP 12 months after TBI.

No adolescent developed a gonadotropin deficiency or pubertal delay; on the other hand, not all children had started puberty. However, in previous retrospective (12) and prospective $(12,14)$ studies in which few cases of gonadotropin deficiencies were reported, no new cases of hypogonadism were reported at more than 1 year post TBI; it was thus suggested (19) that hypogonadism is usually transient.

TSH dysfunction was observed in two patients 1 year post TBI and remained permanent for several years after injury. The other patients did not develop TSH dysfunction during follow-up. Previous studies reported transient TSH dysfunction, and permanent thyroid insufficiency seems rare several years post TBI $(19,20,24$, 27). However, in a study by Heather (56), subtle changes in thyroid function were reported in children 6 years after TBI, and it was hypothesised that TSH dysfunction could be more frequent than expected.

We observed no new case of adrenal insufficiency. The ACTH deficiency observed 1 year post TBI in one patient remained persistent for many years before a spontaneous recovery. A prospective study in adults (29) reported recovery of ACTH function in patients 3 years after mild TBI and persistent ACTH deficiency in one patient 3 years after severe TBI. A spontaneous recovery has been previously described in two children 5 and 8 years after severe TBI $(57,58)$.

We observed no case of hyperprolactinemia that may occur after TBI and can reflect stalk injury. It is usually transient and resolves within the first years after injury. There were no paediatric reports of elevated PRL more than 2 years after injury (19). The mechanisms of recovery are not explained, the pathophysiology of hypothalamopituitary dysfunction after TBI remaining not fully understood.

Unfortunately, severe TBI in children is not a rare event, thus, prolonged endocrine evaluation of all these patients is a challenge. Pituitary deficiency and CPP do not affect the majority of patients, but may contribute significantly to the morbidity following severe TBI. Also, it is essential to be able to determine a population at high risk of pituitary dysfunction. In previous studies $(59,60)$ it was observed that diffuse axonal injury on brain imaging or basal skull fracture conferred an increased risk of pituitary deficiency. In our study, initial post-TBI imaging failed to reveal any consistent relationship between the site or type of cranial and cerebral lesions and permanent pituitary dysfunction and CPP several years after TBI. MRI is more sensitive than CT in the identification of diffuse axonal injury (61) but unfortunately only a few children of our study had MRI available post TBI. Therefore, we were not able to identify more precise radiological predictors of post-TBI pituitary dysfunction.

A pituitary dysfunction one year after severe TBI was associated with GHD or CPP, observed many years after severe TBI. On the other hand, the normality of the pituitary function 1 year post TBI cannot totally reassure on the hormonal evolution since GHD or CPP can appear several years later. However, although we have not been able to definitely identify strong predictive factors, the group of children with pituitary deficiency one-year after severe TBI represents a high-risk group.

In conclusion, severe TBI in childhood is a cause of permanent pituitary deficiency, mostly GHD, and of CPP. Our results lead us to recommend hormonal assessment including dynamic GH testing in children 1 year after severe TBI. In case of pituitary dysfunction at this time, paediatric endocrinologist should initiate a close and prolonged monitoring of growth and pubertal development in order to detect a decreased HV or early signs of PP as soon as possible. Recommendations should be elaborated for patients and their parents, and for the treating physicians. In case of normal pituitary function one-year post-TBI, a coordinated approach by the family, treating physicians, the paediatric neurologist and specialists of paediatric neurorehabilitation units is fully recommended to detect growth anomalies or abnormal pubertal maturation. If clinical abnormalities are suspected, children should then be referred to the paediatric endocrinologist, in order to plan in-depth assessment and implement and monitor treatment and subsequent evolution as needed. 


\section{Declaration of interest}

The authors declare that there is no conflict of interest that could be perceived as prejudicing the impartiality of this study.

\section{Funding}

This work was partially supported by an educational grant from Pfizer SAS grant (number 8501577006). The sponsor was not involved in data collection, manuscript preparation, or publishing decisions.

\section{Acknowledgements}

The authors thank Doctor Laura G Gonzalez, MD (Paediatric Endocrinology, Gynaecology and Diabetology Unit, Necker Enfants-Malades University Hospital) for her help in correcting the English of our manuscript.

\section{References}

1 Faul M, Xu L, Wald MM, Coronado VG \& Dellinger AM. Traumatic brain injury in the United States: national estimates of prevalence and incidence, 2002-2006. Injury Prevention 201016 A268-A268. (https://doi.org/10.1136/ip.2010.029215.951)

2 Shao J, Zhu H, Yao H, Stallones L, Yeates K, Wheeler K \& Xiang H. Characteristics and trends of pediatric traumatic brain injuries treated at a large pediatric medical center in China, 2002-2011. PLoS ONE 20137 e51634. (https://doi.org/10.1371/journal.pone.0051634)

3 Majdan M, Plancikova D, Brazinova A, Rusnak M, Nieboer D, Feigin V \& Maas A. Epidemiology of traumatic brain injuries in Europe: a cross-sectional analysis. Lancet Public Health 20161 e76-e83. (https://doi.org/10.1016/S2468-2667(16)30017-2)

4 Javouhey E, Guérin AC \& Chiron M. Incidence and risk factors of severe traumatic brain injury resulting from road accidents: a population-based study. Accident, Analysis and Prevention 200638 225-233. (https://doi.org/10.1016/j.aap.2005.08.001)

5 Feigin VL, Theadom A, Barker-Collo S, Starkey NJ, McPherson K, Kahan M, Dowell A, Brown P, Parag V, Kydd R et al. Incidence of traumatic brain injury in New Zealand: a population-based study. Lancet Neurology 201312 53-64. (https://doi.org/10.1016/S14744422(12)70262-4)

6 Teasdale G \& Jennett B. Assesment of coma and impaired consciousness. A practical scale. Lancet 19742 81-84. (https://doi. org/10.1016/S0140-6736(74)91639-0)

7 Keenan HT \& Bratton SL. Epidemiology and outcomes of pediatric traumatic brain injury. Developmental Neuroscience 200628 256-263. (https://doi.org/10.1159/000094152)

8 Babikian T \& Asarnow R. Neurocognitive outcomes and recovery after pediatric TBI: meta-analytic review of the literature. Neuropsychology 200923 283-296. (https://doi.org/10.1037/ a0015268)

9 Li L \& Liu J. The effect of pediatric traumatic brain injury on behavioral outcomes: a systematic review. Developmental Medicine and Child Neurology 201355 37-45. (https://doi.org/10.1111/j.14698749.2012.04414.x)

10 McCarthy ML, MacKenzie EJ, Durbin DR, Aitken ME, Jaffe KM, Paidas CN, Slomine BS, Dorsch AM, Christensen JR, Ding R et al. Health-related quality of life during the first year after traumatic brain injury. Archives of Pediatrics and Adolescent Medicine $2006 \mathbf{1 6 0}$ 252-260. (https://doi.org/10.1001/archpedi.160.3.252)

11 Aimaretti G, Ambrosio MR, Di Somma C, Fusco A, Cannavò S, Gasperi M, Scaroni C, De Marinis L, Benvenga S, Degli Uberti EC et al. Traumatic brain injury and subarachnoid haemorrhage are conditions at high risk for hypopituitarism: screening study at
3 months after the brain injury. Clinical Endocrinology 200461 320-326. (https://doi.org/10.1111/j.1365-2265.2004.02094.x)

12 Einaudi S, Matarazzo P, Peretta P, Grossetti R, Giodarno F, Altare F, Bondone C, Andreo M, Ivani G, Genitori L et al. Hypothalamohypopyseal dysfunction after traumatic brain injury in children and adolescents: a preliminary retrospective and prospective study. Journal of Pediatric Endocrinology and Metabolism 200619 691-703.

13 Niederland T, Makovi H, Gal V, Andreka B, Abraham CS \& Kovacs J. Abnormalities of pituitary function after traumatic brain injury in children. Journal of Neurotrauma 200724 119-127. (https://doi. org/10.1089/neu.2005.369ER)

14 Poomtavorn P, Maixner W \& Zacharin M. Pituitary function in paediatric survivors of severe traumatic brain injury. Archives of Disease in Childhood 200893 133-137. (https://doi.org/10.1136/ adc.2007.121137)

15 Auble BA, Bollepalli S, Makoroff K, Weis T, Khoury J, Colliers T \& Rose SR. Hypopituitarism in pediatric survivors of inflicted traumatic brain injury. Journal of Neurotrauma 201431 321-326. (https://doi. org/10.1089/neu.2013.2916)

16 Casano-Sancho P. Pituitary dysfunction after traumatic brain injury: are there definitive data in children? Archives of Disease in Childhood 2017102 572-577. (https://doi.org/10.1136/ archdischild-2016-311609)

17 Aimaretti G, Ambrosio MR, Di Somma C, Gasperi M, Cannavò S, Scaroni C, De Marinis L, Baldelli R, Bona G, Giordano G et al. Hypopituitarism induced by traumatic brain injury in the transition phase. Journal of Endocrinological Investigation 200528 984-989. (https://doi.org/10.1007/BF03345336)

18 Norwood KW, DeBoer MD, Gurka MJ, Kuperminc MN, Rogol AD, Blackman JA, Wamstad JB, Buck ML \& Patrick PD. Traumatic brain injury in children and adolescents: surveillance for pituitary dysfunction. Clinical Pediatrics 201049 1044-1049. (https://doi. org/10.1177/0009922810376234)

19 Kaulfers AM, Backeljauw PF, Reifschneider K, Blum S, Michaud L, Weiss M \& Rose SR. Endocrine dysfunction following traumatic brain injury in children. Journal of Pediatrics 2010157 894-899. (https:// doi.org/10.1016/j.jpeds.2010.07.004)

20 Casano-Sancho P, Suarez L, Ibanez L, García-Fructuoso G, Medina J, Febrer A \& Garcia-Fructuoso G. Pituitary dysfunction after traumatic brain injury in children: is there a need for ongoing endocrine assessment? Clinical Endocrinology 201379 853-858. (https://doi. org/10.1111/cen.12237)

21 Krahulik D, Aleksijevic D, Smolka V, Klaskova E, Venhacova P, Vaverka M, Mihal V \& Zapletalova J. Prospective study of hypothalamo-hypophyseal dysfunction in children and adolescents following traumatic brain injury. Biomedical Papers of the Medical Faculty of the University Palacký, Olomouc, Czech Republic 2017161 80-85. (https://doi.org/10.5507/bp.2016.047)

22 McDonald A, Lindell M, Dunger DB \& Acerini CL. Traumatic brain injury is a rarely reported cause of growth hormone deficiency. Journal of Pediatrics 2008152 590-593. (https://doi.org/10.1016/j. jpeds.2007.12.046)

23 Khadr SN, Crofton PM, Jones PA, Wardhaugh B, Roach J, Drake AJ, Minns RA \& Kelnar CJ. Evaluation of pituitary function after traumatic brain injury in childhood. Clinical Endocrinology 201073 637-643. (https://doi.org/10.1111/j.1365-2265.2010.03857.x)

24 Heather NL, Jefferies C, Hofman PL, Derraik JGB, Brennan C, Kelly P, Hamill JKM, Jones RG, Rowe DL \& Cutfield WS. Permanent hypopituitarism is rare after structural traumatic brain injury in early childhood. Journal of Clinical Endocrinology and Metabolism 201297 599-604. (https://doi.org/10.1210/jc.2011-2284)

25 Reifschneider K, Auble BA \& Rose SR. Update of endocrine dysfunction following pediatric traumatic brain injury. Journal of Clinical Medicine 20154 1536-1560. (https://doi.org/10.3390/ jcm4081536) 
26 Quinn M \& Agha A. Post-traumatic hypopituitarism-who should be screened, when, and how? Frontiers in Endocrinology 201898. (https://doi.org/10.3389/fendo.2018.00008)

27 Ghigo E, Masel B, Aimaretti G, Léon-Carrión J, Casanueva FF, Domonguez-Morales MR, Elovic E, Perrone K, Stalla G, Thompson C et al. Consensus guidelines on screening for hypopituitarism following traumatic brain injury. Brain Injury 200519 711-724. (https://doi.org/10.1080/02699050400025315)

28 Aimaretti G, Ambrosio MR, Di Somma C, Gasperi M, Cannavo S, Scaroni C, Fusco A, Del Monte P, De Menis E, Faustini-Fustini M et al. Residual pituitary function after brain injury-induced hypopituitarism: a prospective 12-month study. Journal of Clinical Endocrinology and Metabolism 200590 6085-6092. (https://doi. org/10.1210/jc.2005-0504)

29 Tanriverdi F, Halil Ulutabanca H, Unluhizarci K, Selcuklu A, Casanueva FF \& Kelestimur F. Three years prospective investigation of anterior pituitary function after traumatic brain injury: a pilot study. Clinical Endocrinology 200868 573-579. (https://doi. org/10.1111/j.1365-2265.2007.03070.x)

30 Wamstad JB, Norwood KW, Rogol AD, Gurka MJ, Deboer MD, Blackman JA, Buck ML, Kuperminc MN, Darring JG \& Patrick PD. Neuropsychological recovery and quality-of-life in children and adolescents with growth hormone deficiency following TBI: a preliminary study. Brain Injury 201327 200-208. (https://doi.org/10 3109/02699052.2012.672786)

31 Kelly DF, McArthur DL, Levin H, Swimmer S, Dusick JR, Cohan P, Wang C \& Swerdloff R. Neurobehavioral and quality of life changes associated with growth hormone insufficiency after complicated mild, moderate, or severe traumatic brain injury. Journal of Neurotrauma 200623 928-942. (https://doi.org/10.1089/ neu.2006.23.928)

32 Personnier C, Crosnier H, Meyer P, Chevignard M, Flechtner I, Boddaert N, Breton S, Mignot C, Dassa Y, Souberbielle JC et al. Prevalence of pituitary dysfunction after severe traumatic brain injury in children and adolescents: a large prospective study. Journal of Clinical Endocrinology and Metabolism 201499 2052-2060. (https:// doi.org/10.1210/jc.2013-4129)

33 Kochanek PM, Carney N, Adelson PD, Ashwal S, Bell MJ, Bratton S, Carson S, Chesnut RM, Ghajar J, Goldstein B et al. Guidelines for the acute medical management of severe traumatic brain injury in infants, children, and adolescents-second edition. Pediatric Critical Care Medicine 201213 (Supplement 1) S1-S82. (https://doi. org/10.1097/PCC.0b013e31823f435c)

34 Sempé M, Pedron G \& Roy MP. Auxologie, Méthodes et Séquences. Paris: Theraplix, 1979.

35 Rolland-Cachera MF, Cole TJ, Sempe M, Tichet J, Rossignol C \& Charraud A. Body mass index variations: centiles from birth to 87 years. European Journal of Clinical Nutrition 1991 45 13-21.

36 Tanner JM \& Whitehouse RH. Clinical longitudinal standards for height, weight, height velocity, weight velocity, and stages of puberty. Archives of Disease in Childhood 197651 170-179. (https:// doi.org/10.1136/adc.51.3.170)

37 Cole TJ. Galton's midparent height revisited. Annals of Human Biology 200027 401-405. (https://doi.org/10.1080/03014460050044874)

38 Society GR. Consensus guidelines for the diagnosis and treatment of growth hormone (GH) deficiency in childhood and adolescence: summary statement of the GH Research Society. Journal of Clinical Endocrinology and Metabolism 200085 3990-3993. (https://doi. org/10.1210/jc.85.11.3990)

39 Thomas M, Massa G, Craen M, de Zegher F, Bourguignon JP, Heinrichs C, De Schepper J, Du Caju M, Thiry-Counson G \& Maes M. Prevalence and demographic features of childhood growth hormone deficiency in Belgium during the period 1986-2001. European Journal of Endocrinology 2004151 67-72. (https://doi.org/10.1530/ eje.0.1510067)
40 Nemes O, Kovacs N, Czeiter E, Kenyeres P, Tarjanyi Z, Bajnok L, Buki A, Doczi T \& Mezosi E. Predictors of post-traumatic pituitary failure during long-term follow-up. Hormones 201514 383-391. (https://doi.org/10.14310/horm.2002.1564)

41 Spaw AJ, Lundine JP, Johnson SA, Peng J, Wheeler KK, Shi J, Yang G, Haley KJ, Groner JI \& Xiang H. Follow-up care adherence after hospital discharge in children with traumatic brain injury. Journal of Head Trauma Rehabilitation 201833 E1-E10. (https://doi. org/10.1097/HTR.0000000000000314)

42 Carel JC, Tesca JP, Letrait M, Chaussain JL, Lebouc Y, Job JC \& Coste J. GH values growth hormone testing for the diagnosis of growth hormone deficiency in childhood: a population registerbased study. Journal of Clinical of Endocrinology and Metabolism 1997 82 2117-2121. (https://doi.org/10.1210/jcem.82.7.4106)

43 Ranke MB. Growth hormone deficiency: diagnostic principles and practices. In Diagnostic of Endocrine Function in Children and Adolescents. pp 102-137. Eds MP Ranke \& PE Mullis. Basel: Karger, 2011. (https://doi.org/10.1159/isbn.978-3-8055-9415-8)

44 Bellone S, Einaudi S, Caputo M, Prodam F, Busti A, Belcastro S, Parlamento S, Zavattaro M, Verna F, Bondone C et al. Measurement of height velocity is an useful marker for monitoring pituitary function in patients who had traumatic brain injury. Pituitary 2013 16 499-506. (https://doi.org/10.1007/s11102-012-0446-0)

45 Moon RJ, Wilson P, Kirkham FJ \& Davies JH. Growth monitoring following traumatic brain injury. Archives of Disease in Childhood 200994 699-701. (https://doi.org/10.1136/adc.2008.145235)

46 van Pareren YK, Duivenvoorden HJ, Slijper FS, Koot HM \& HokkenKoelega AC. Intelligence and psychosocial functioning during long-term growth hormone therapy in children born small for gestational age. Journal of Clinical Endocrinology and Metabolism 2004 89 5295-5302. (https://doi.org/10.1210/jc.2003-031187)

47 Siemensma EPC, Tummers-de Lind van Wijngaarden RFA, Festen DAM, Troeman ZCE, van Alfen-van der Velden AAEM(, Otten BJ, Rotteveel J, Odink RJH, Bindels-de Heus GCB, van Leeuwen $\mathrm{M}$ et al. Beneficial effects of growth hormone treatment on cognition in children with Prader-Willi syndrome: a randomized controlled trial and longitudinal study. Journal of Clinical Endocrinology and Metabolism 201297 2307-2314. (https://doi. org/10.1210/jc.2012-1182)

48 Reimunde P, Quintana A, Castanon B, Casteleiro N, Vilamovo Z, Otero A, Devesa A, Otero-Cepeda XL \& Devesa J. Effects of growth hormone $(\mathrm{GH})$ replacement and cognitive rehabilitation in patients with cognitive disorders after traumatic brain injury. Brain Injury 201125 65-73. (https://doi.org/10.3109/02699052.2010.536196)

49 Moreau OK, Cortet-Rudelli C, Yollin E, Merlen E, Daveluy W \& Rousseaux M. Growth hormone replacement therapy in patients with traumatic brain injury. Journal of Neurotrauma $2013 \mathbf{3 0}$ 998-1006. (https://doi.org/10.1089/neu.2012.2705)

50 Devesa J, Reimunde P, Devesa P, Barberá M \& Arce V. Growth hormone (GH) and brain trauma. Hormones and Behavior 201363 331-344. (https://doi.org/10.1016/j.yhbeh.2012.02.022)

51 Devesa J, Alonso B, Casteleiro N, Couto P, Castañón B, Zas E \& Reimunde P. Effects of recombinant growth hormone (GH) replacement and psychomotor and cognitive stimulation in the neurodevelopment of GH-deficient (GHD) children with cerebral palsy: a pilot study. Therapeutics and Clinical Risk Management 20117 199-206. (https://doi.org/10.2147/TCRM.S21403)

52 Klose M, Stochholm K, Janukonyté J, Christensen LL, Cohen AS, Wagner A, Laurberg P, Christiansen JS, Andersen M \& FeldtRasmussen U. Patient reported outcome in posttraumatic pituitary deficiency: results from the Danish National Study on posttraumatic hypopituitarism. European Journal of Endocrinology 2015172 753-762. (https://doi.org/10.1530/EJE-14-1069)

53 Sørensen K, Mouritsen A, Aksglaede L, Hagen CP, Mogensen SS \& Juul A. Recent secular trends in pubertal timing: implications for 
evaluation and diagnosis of precocious puberty. Hormone Research in Paediatrics 201277 137-145. (https://doi.org/10.1159/000336325)

54 Le Moal J, Rigou A, Le Tertre A, De Crouy-Channel P, Léger J \& Carel JC. Marked geographic patterns in the incidence of idiopathic central precocious puberty: a nationwide study in France. European Journal of Endocrinology 2018178 33-41. (https://doi.org/10.1530/ EJE-17-0379)

55 De Sanctis V, Soliman AT, Elsedfy H, Soliman NA, Elalaily R \& El Kholy M. Precocious puberty following traumatic brain injury in early childhood: a review of the literature. Pediatric Endocrinology Reviews 201513 458-464.

56 Heather NL, Derraik JGB, Chiavaroli V, Hofman PL \& Cutfield WS. Increasing severity of traumatic brain injury in early childhood is associated with a progressive reduction in long-term serum thyroidstimulating hormone concentrations. Clinical Endocrinology 201684 463-465. (https://doi.org/10.1111/cen.12953)

57 Eiholzer U, Zachmann M, Gnehm HE \& Prader A. Recovery from post-traumatic anterior pituitary insufficiency. European
Journal of Pediatrics 1986145 128-130. (https://doi.org/10.1007/ BF00441873)

58 Agha A, Ryan J, Sherlock M \& Thompson CJ. Spontaneous recovery from posttraumatic hypopituitarism. American Journal of Physical Medicine and Rehabilitation 200584 381-385. (https://doi. org/10.1097/01.PHM.0000156898.47097.93)

59 Schneider M, Schneider HJ, Yassouridis A, Saller B, von Rosen F \& Stalla GK. Predictors of anterior pituitary insufficiency after traumatic brain injury. Clinical Endocrinology 200868 206-212. (https://doi. org/10.1111/j.1365-2265.2007.03020.x)

60 Nemes O, Kovacs N, Czeiter E, Kenyeres P, Tarjanyi Z, Bajnok L, Buki A, Doczi T \& Mezosi E. Predictors of post-traumatic pituitary failure during long-term follow-up. Hormones 201514 383-391. (https://doi.org/10.14310/horm.2002.1564)

61 Azouvi P. Neuroimaging correlates of cognitive and functional outcome after traumatic brain injury. Current Opinion in Neurology 200013 665-669. (https://doi.org/10.1097/00019052-20001200000009)

Received 16 January 2019

Revised version received 1 March 2019

Accepted 7 March 2019 